\title{
AN ALTERNATIVE AND SIMPLE MANNER TO CALCULATE THE THERMAL EFFICIENCY OF COMBUSTION ENGINES
}

\author{
F. N. C. Rocha ${ }^{a}$, \\ J. A. Martins ${ }^{b}$, \\ and E. C. Romão \\ ${ }^{a}$ Universidade Federal de Itajubá \\ Campus Avançado de Itabira \\ Rua Irmão Ivone Drumond, 200 \\ Distrito Industrial II \\ CEP. 35903-087, Itabira, MG, Brasil \\ buniversidade Estadual de Campinas \\ Faculdade de Engenharia Mecânica \\ Departamento de Engenharia de Materiais \\ Rua Mendeleyev, 200 \\ Cidade Universitária "Zeferino Vaz" \\ Distrito de Barão Geraldo \\ CEP. 13083-860, Campinas, SP, Brasil \\ 'Universidade de São Paulo \\ Departamento de Ciências Básicas e Ambientais \\ Estrada do Campinho, s/n, Bairro Campinho \\ CEP. 12602-810, Lorena, SP, Brasil \\ Received: April 7, 2014 \\ Revised: May 7, 2014 \\ Accepted: June 7, 2014 \\ ABSTRACT \\ This papers aims to present techniques and methods to develop an \\ alternative equation to determine the thermal efficiency of internal \\ combustion engines. Towards interpolation of data, obtained from \\ thermodynamic tables, it presents a function that allows a faster calculation \\ of efficiency for combustion engines. \\ Keywords: Otto cycle, thermal efficiency, combustion.
}

\section{NOMENCLATURE}

$\begin{array}{ll}q_{e} & \text { heat input } \\ r & \text { compression rate } \\ s & \text { entropy } \\ T & \text { temperature } \\ u & \text { internal energy }\end{array}$

\section{Greek symbols \\ $v \quad$ specific volume \\ $v_{r} \quad$ relative specific volume}

\section{INTRODUCTION}

The internal combustion engines are one of the most important mechanical systems (driving mechanism) by chemical source in the contemporary and modern world. These are responsible for the movement of ships, boats, small airplanes, generators, among several other. This paper studies the combustion engines process characterized by a cycle of particular phases. The phases or steps per cycle are described as follow; isobaric inlet, adiabatic compression, isovolumetric combustion and isobaric outlet, see Fig. 1 (Çengel and Boles, 2006). Developed originally by Beau de Rochas at 1861 the cycle was definitively implemented only by Nikolaus Otto, in cooperation with other scientists in that age, fifteen years ahead, at 1876. Since then, the combustion engines have being improved and new models developed.

One of the main interests of engineers is the efficiency of machines and equipment. Very oftennew researches objective to mitigate energy losses and improve energy outputs. Nevertheless, the combustion engine is also included in such interest, 
which has grown substantially since its invention. Despite of engines based on diesel fuel allow a higher thermal efficiency, its utilization is limited due to higher costs. Notice that the thermal efficiency links with temperature; in diesel engines the highest compression rates allows higher temperatures, improving its efficiency. In consequence, higher forces are applied on the piston, connecting rod, crankshaft and all parts into the combustion engine. In order to absorb such higher loads is necessary to build engines with stronger materials, on the other hand the cost of final product increases.

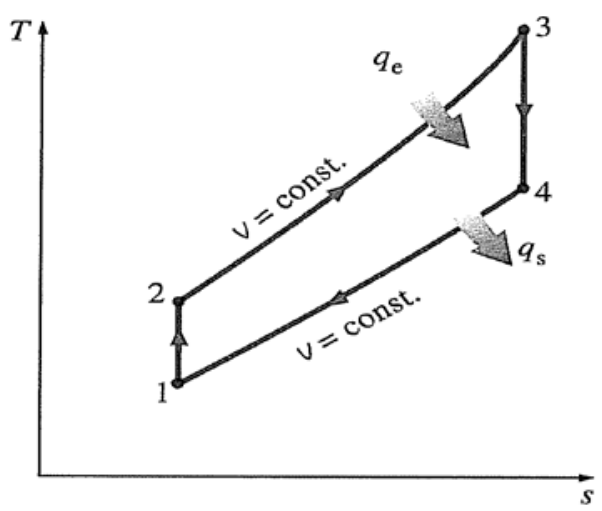

Figure 1. Diagram Temperature (T) - Entropy (s) Ideal Otto Cycle (Çengel and Boles, 2006).

The aim purpose of this paper is to develop an alternative method that allows the user to determine the efficiency of Combustion Engines, by using a limited number of inputs. In order to do so, a data analysis is done and give basis to create a function dependable only of; initial temperature $\left(\boldsymbol{T}_{\mathbf{1}}\right)$, compression rate $(\boldsymbol{r})$ and heat input $\left(\boldsymbol{q}_{\mathbf{e}}\right)$. By means of this function, is implemented a method to calculate the thermal efficiency in computational software's, reducing substantially the process time. This last in replacement of traditional methods that make use of thermodynamics tables.

\section{DETERMINING THE EQUATIONS}

In order to find a function of type $\eta=f\left(T_{1}, r, q_{e}\right)$ based on the definitions shown by (Çengel and Boles, 2006) for an ideal combustion cycle, there are the following steps along the process- cycle to understand, (see Fig. 1) as follow;

1-2 Iso-enthropic compression (isobaric inlet);

2-3 Heat input under constant volume (adiabatic compression);

3-4 Iso-entropic expansion (iso-volumetric combustion); outlet);

4-1 Heat outlet under constant volume (isobaric

from the process phase (steps) above is defined the following equation;

$$
n=1-\frac{u_{4}-u_{1}}{q_{e}}
$$

where $u_{1}$ and $u_{4}$ are the particular energies in the phase 1 and 4 respectively (Fig. 1) and $q_{e}$ the inlet energy. Now the main objective is to define $\mathrm{u}_{1}$ and $\mathrm{u}_{4}$ once $q_{\mathrm{e}}$ is an important input.

Beginning with the phase 1-2 the following properties are defined as follow;

$$
u^{\prime}=u^{\prime}(T)
$$

where $u^{\prime}$ is a function where the input is given by " $K$ " and the output is the specific internal energy $(\mathrm{kJ} / \mathrm{kg})$ being;

$$
v_{r}^{\prime}=v_{r}^{\prime}(T)
$$

where $v_{r}^{\prime}$ is a function where the input is given by "K" and return the relative specific volume $\left(v_{r}\right)$.

Thereby, it is defined the value of the specific volume at point 2 as a function of the relative specific volume at point 1 and also the compression rate, by the following equation,

$$
v_{r_{2}}=\frac{v_{r_{1}}}{r}
$$

As a result of the Eq. (4) and with Eq. (2) is listed the specific internal energy at point 2 with the input values ahead;

$$
u_{2}=u^{\prime \prime}\left(v_{r_{2}}\right)=u^{\prime \prime}\left(\frac{v_{r_{1}}}{r}\right)
$$

where

$$
u^{\prime \prime}=u^{\prime \prime}\left(v_{r}\right)
$$

in other words, $u$ " is a function where the input is the relative specific volume and this last return the value of the specific internal energy $(\mathrm{kJ} / \mathrm{kg})$.

Now, in the phase 2-3 (Fig. 1), where there is the heat input, is possible to correlate the specific internal energy at point 2 with the heat input and then defining the specific internal energy at the point 3, towards the following equation;

$$
u_{3}=u_{2}+q_{e} \Rightarrow u_{3}=u^{\prime \prime}\left(\frac{v_{r}^{\prime}\left(T_{1}\right)}{r}\right)+q_{e}
$$

Finding $u_{3}$ from Eq. (7) is possible then to reach the value of $v_{r_{3}}$ at the following manner; 


$$
v_{r_{3}}=v_{r}^{\prime \prime}\left(u_{3}\right)
$$

where

$$
v_{r}^{\prime \prime}=v_{r}^{\prime \prime}(u)
$$

where $v_{r}^{\prime \prime}$ is a funtion where the input is the specific internal energy $(\mathrm{kJ} / \mathrm{kg})$ and the output is the relative specific volume.

In order to close the process phases, in the step 3-4 is found the values of $v_{r}^{\prime \prime}$ and $u_{4}$ as below;

$$
\begin{gathered}
v_{r_{4}}=v_{r_{3}} \cdot r=v_{r}^{\prime \prime}\left(u_{3}\right) \cdot r= \\
v_{r}^{\prime \prime}\left(u^{\prime \prime}\left(\frac{v_{r}^{\prime}\left(T_{1}\right)}{r}\right)+q_{e}\right) \cdot r \\
u_{4}=u^{\prime \prime}{ }^{\left(v_{r_{4}}\right)}= \\
u^{\prime \prime}\left(v_{r}^{\prime \prime}\left(u^{\prime \prime}\left(\frac{v_{r}^{\prime}\left(T_{1}\right)}{r}\right)+q_{e}\right) \cdot r\right)
\end{gathered}
$$

Discovering by the Eq. (2) that $u_{1}=u^{\prime}\left(T_{1}\right)$ and making use of the results from Eq. (11) and Eq. (1), the equation is rewritten at the following manner, as follow;

$$
\begin{aligned}
& n=1-\frac{u_{4}-u_{1}}{q_{e}}= \\
& 1-\frac{u^{\prime \prime}\left(v_{r}^{\prime \prime}\left(u^{\prime \prime}\left(\frac{v_{r}^{\prime}\left(T_{1}\right)}{r}\right)+q_{e}\right) \cdot r\right)-u^{\prime}\left(T_{1}\right)}{q_{e}}
\end{aligned}
$$

\section{METHODS OF ANALYSIS OF DATA AND RESULTS}

Before of anything, it is necessary to define the function of Eqs. (2), (3), (6) and (9). In order to determine such functions, initially is necessary to reduce the interval $\mathrm{f}$ of interest, in other words, to determine the temperature range where the engine might work. The temperature chosen is $270 \mathrm{~K}$ and is sufficiently low for countries like Brazil where rarely low temperatures are registered. In terms of maximum temperature, in (Leff, 1987) is presented the temperature of combustion cycle within 1,420 e $1,890 \mathrm{~K}$, reaching peaks of $2,500 \mathrm{~K}$ or even higher in a restrict interval at the spark moment in the explosion phase. Nevertheless, those values should be limited by the mechanical characteristics of the material applied, such as melting point and time associated. Having this in mind, it is selected the maximum temperature of $2,000 \mathrm{~K}$, not too high as $2,500 \mathrm{~K}$, as but higher than $1,890 \mathrm{~K}$ (regular engine temperature) and coherent with the process. It is important to reinforce that the function is only optimized to this interval $(270-2,000 \mathrm{~K})$ but whether is desired to work within different values, it is also possible, but having in mind that higher errors are expected when compared with those presented in this paper.

The Software Origin ${ }^{\circledR}$ was used as well as the errors analysis by Software Microsoft Excel ${ }^{\circledR}$ due to interpolation of the results. The first function determined was the internal energy versus temperature. Its behavior almost linear makes the calculations easier and provide a better adjustment of the function. The selected function, on the other hand, is not linear (type $a x+b$ ) once the errors associated would be relatively higher, therefore an exponential function was chosen and the average error is $0.624 \%$ while the maximum $2.052 \%$ occurs at 270K, as follow;

$$
u^{\prime}(T)=-3905.39507+3900.34921 \cdot e^{\frac{T}{5570.8207}}
$$

To make the function visualization and error easier, the two graphs below are shown (Fig. 2).

In the first graph (Fig. 2) it is possible to see the function $u^{\prime}(T)$ based on Eq. (13) and the values tabled as (Çengel and Boles, 2006). Now in the second graph it is possible to verify the percentage error, notice that most of the points correspond to errors lower than $1 \%$.
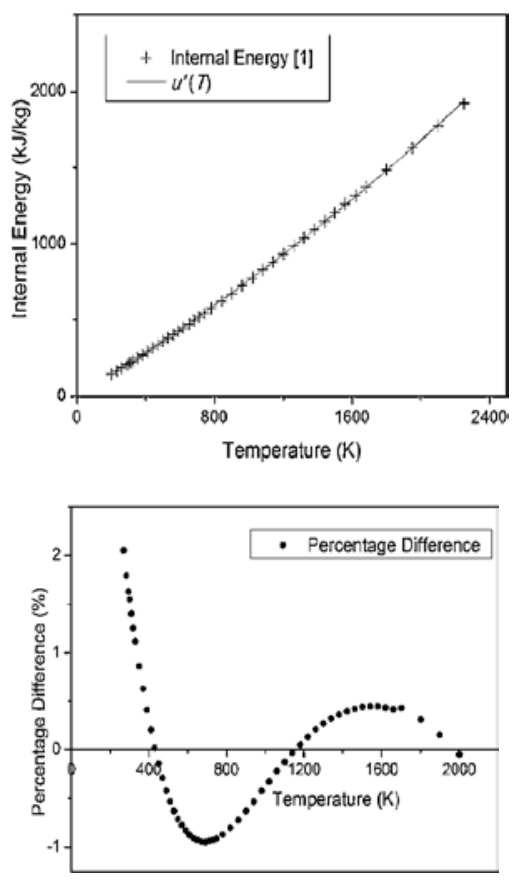

Figure 2. The former is a comparison of the function with tabled values and the latter is the error in percentage. 
The volume as a function of temperature is the next to analyze, below is found the function where the average error is $0.286 \%$ and maximum $1.546 \%$ occurred at $1,700 \mathrm{~K}$. It is verified extremely low values, increasing subsequently the reliability of the method developed. The function mentioned follows;

$$
\begin{aligned}
v_{r}^{\prime}(T)= & -2474.29447 \cdot e^{\frac{-T}{149.61758}}+20543.56705 . \\
& e^{\frac{-T}{61.80388}}+273.35022 \cdot e^{\frac{-T}{389.23662}}+1.19183
\end{aligned}
$$

In Fig. 3, first graph, the function $v_{r}^{\prime}(T)$ does not present any type of deviation related to the points of volume, which represent the real values. It is possible only to see that the function is not totally adjusted to the real points in the graph at right, which demonstrate the percentage errors, for which the majority is within $-1 \%$ and $1 \%$. See in Fig. 3, second graph, that the highest errors happen at a region where the function $v_{r}^{\prime}(T)$ has a characteristic almost parallel with the horizontal axle, in order words, the function $v_{r}^{\prime}(T)$ "exponential" is not able to get closer to that region of linear characteristic.
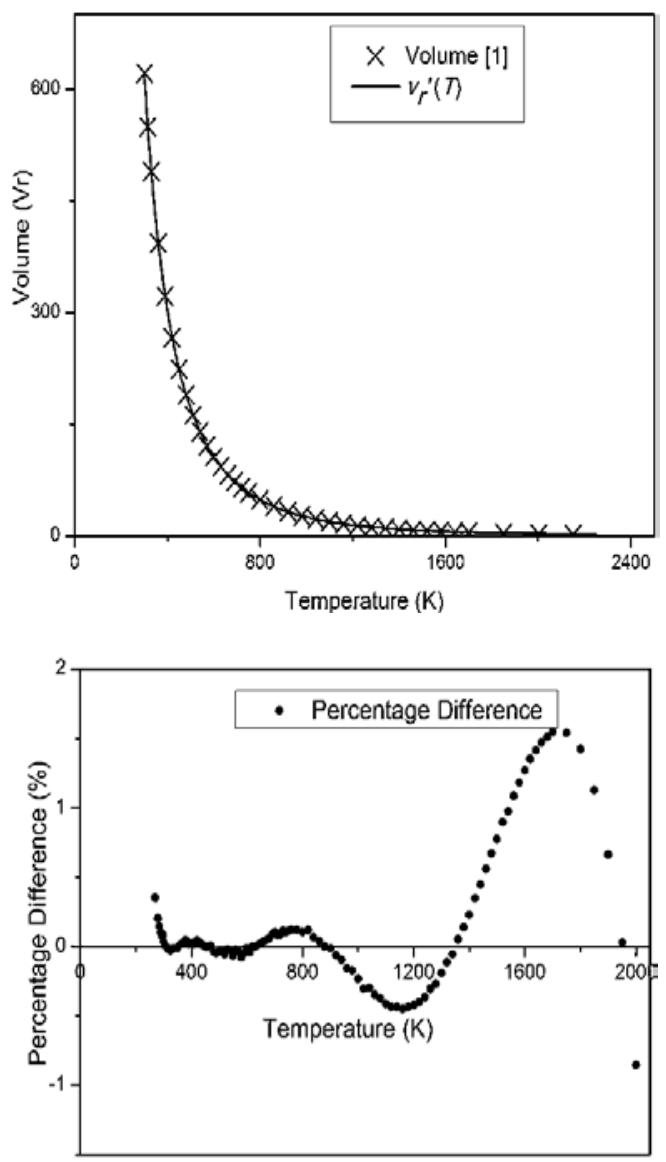

Figure 3. The former is comparison of function volume with the real values and the latter error percentage.
Now the internal energy as a function of volume was reached after several analyses of types of functions, the better adjustment was also by exponential function, but now with some new terms. The average error is $0.791 \%$, the maximum $2.949 \%$ occurring at $270 \mathrm{~K}$. The function is shown below as well as its graph at Fig. 4, together with the percentage errors.
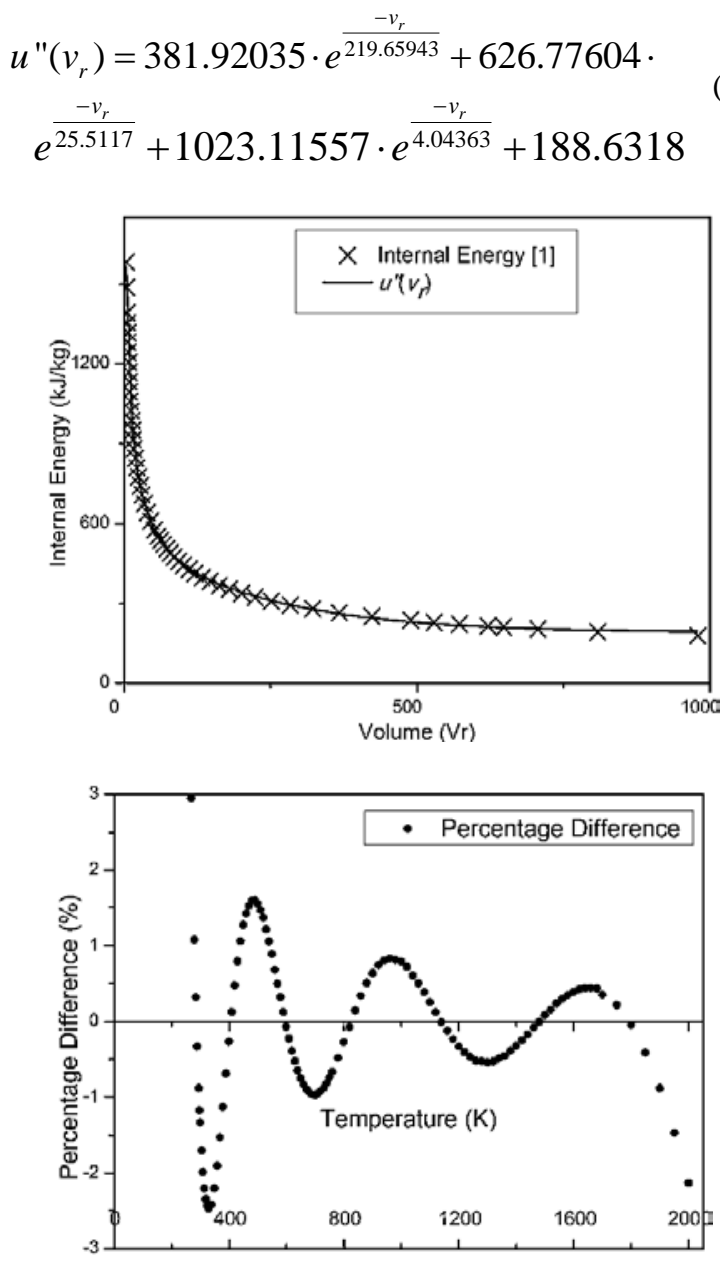

Figure 4. The former is a comparison of the interpolated function with real values and the latter is the percentage error.

The volume of the function of internal energy is an exponential function at the same way of the previous, the average error $0.485 \%$ and maximum $2.583 \%$ occur at $1,700 \mathrm{~K}$. The function $v_{r}^{\prime \prime}(u)$ is represented below and the graph at Fig. 5 shows the percentage values versus temperature.

$$
\begin{aligned}
& v_{r}^{\prime \prime}(u)=213.44503 \cdot e^{\frac{-u}{329.62509}}+2364.449 . \\
& e^{\frac{-u}{110.36649}}+203061.75604 \cdot e^{\frac{-u}{44.64318}}+1.50865
\end{aligned}
$$

Notice that the values of errors are really small and lower than $1 \%$ and higher punctual values, this 
fact enrich the method developed, being adequate to low uncertainties and saving time in certain applications.
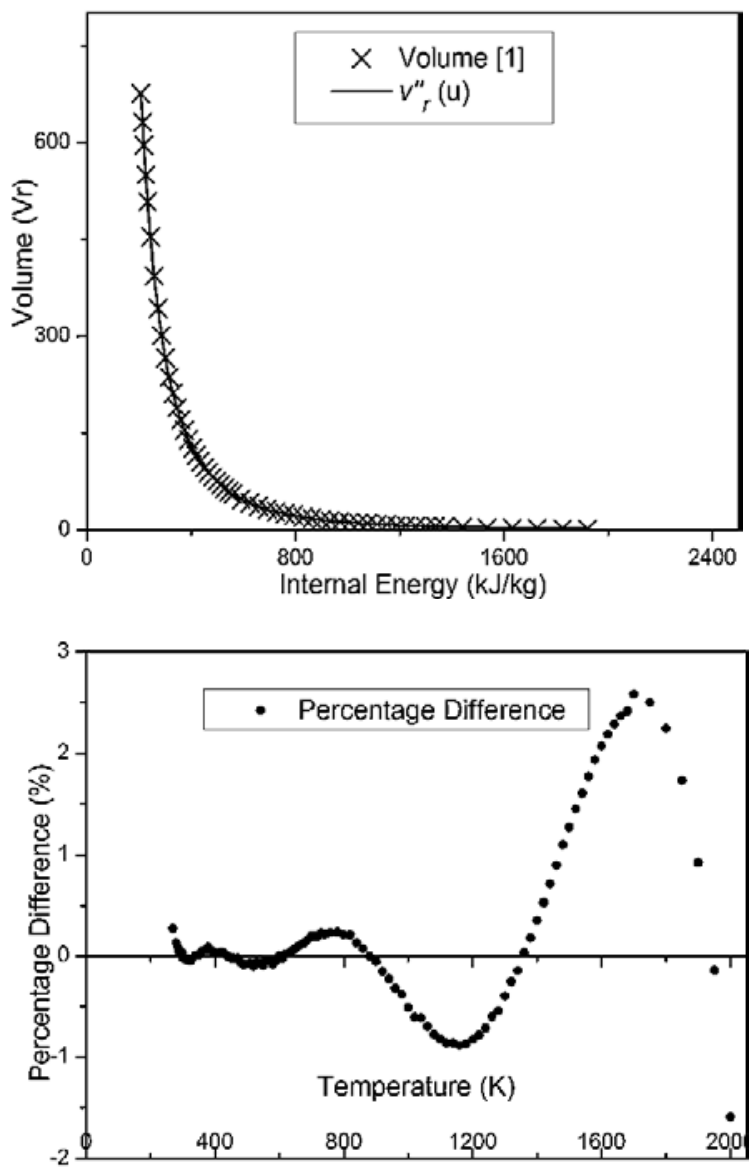

Figure 5. The latter is the percentage error of volume as a function of specific internal energy the former is the function of relative specific volume.

\section{APPLICATIONS OF THE METHOD}

Imagine that is necessary to determine the efficiency of an engine at room temperature $\left(T_{1}\right)$ with the temperature increase, from $270 \mathrm{~K}$ up (approximately $-3^{\circ} \mathrm{C}$ ). Suppose the following data inputs:

- Compression rate : $r=8$;

- Initial temperature: $T_{1}=270 \mathrm{~K}$ until $320 \mathrm{~K}\left(-3^{\circ} \mathrm{C}\right.$ till $47^{\circ} \mathrm{C}$ approximately);

- Inlet energy in the system per cycle: $q_{\mathrm{e}}=800 \mathrm{~kJ}$.

It is possible to proceed the analysis by calculating each value within an interval of $10 \mathrm{~K}$, for example, then the outputs would be calculated to 270 , $280 \ldots 320 \mathrm{~K}$. However is obvious that the usage of the functions here determined with the help of a software like Microsoft Excel ${ }^{\circledR}$ or Origin ${ }^{\circledR}$ is much easier and from this point to build the graph that demonstrates such behavior. Certainly minor deviations are found, in other words, the real values are different from those found by the Eq. (12) for which this situation is lower than $0.5 \%$. Furthermore is necessary to reinforce that the manual calculations, in general, are done by linear interpolation on several points, and this add some errors, small but present.

Beyond of initial temperature is also possible to change the compression rate. The compression rate to engines driven by gasoline varies from 8 to 10 (Çengel and Boles, 2006), but a study realized for engines using ethanol and gasoline mixture, common in Brazil, varied within 10 and 12 (Costa and Sodré, 2011). Therefore, it was decisive to evaluate the effect of the compression rate to engines with values within 8 and 12. It was done in order to evaluate the validity of the equations used in manual calculations and presented an error higher than $0.5 \%$, the graph drawn in Fig. 6 demonstrates the values. Additionally, it is clear that the thermal efficiency growth with the compression rate increasing, the constraint to use the even higher compression rates is the self-ignition of the fuel. This fact can damage seriously the engine once the ignition happens always at the sparking time, synchronized, and never before the right and exact moment (Fig. 7).

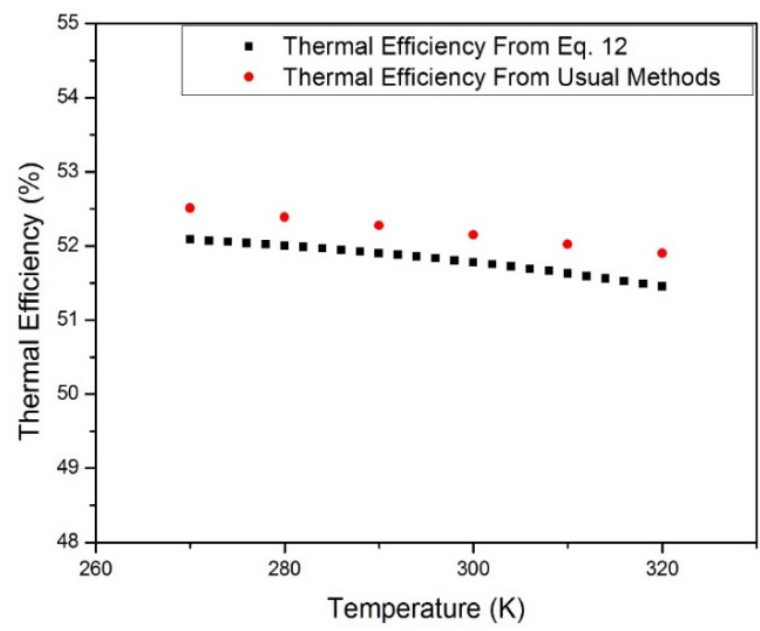

Figure 6. Evaluation of results obtained by Eq. (12).

Lastly, the input energy was changed (Fig. 8), for this, the temperature kept in $300 \mathrm{~K}$, the compression rate 10 and the interval of input in terms of energy 600 up to $1,350 \mathrm{~kJ} / \mathrm{kg}$. A limit of $1,350 \mathrm{~K}$ was defined once superior values are not found in the thermodynamic tables usually met in literature (limit $2,250 \mathrm{~K})$. Also due to the fact the temperature in the mixture cannot reach $2,000 \mathrm{~K}$ or superior, unless in a very restrict interval of time. Mainly because the material of the parts in the engine would not support such heating energy along each cycle in a constant basis. The results are relevant notice that the variation of the energy in the input result in a variation almost linear in the output. Additionally the differences between the results of the calculations made manually, which implies in consults of tables and linear interpolations and from those made by the Eq. 
(12) is very low, $1.99 \%$ for the energy input of $1,350 \mathrm{~kJ} / \mathrm{kg}$. This difference can be explained by the fact that during the process of calculations high values of internal energies are reached, superior of those from the optimized equation.

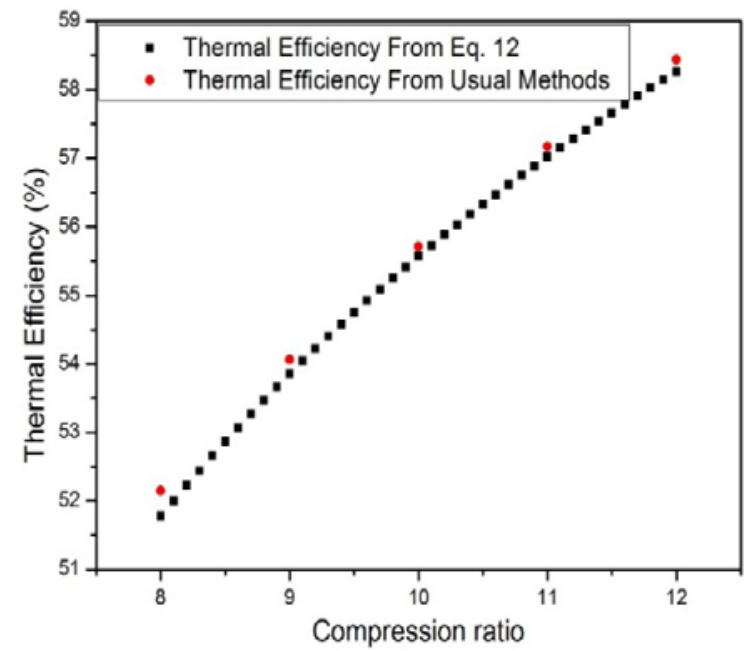

Figure 7. Effect of variation of compression rate in thermal efficiency.

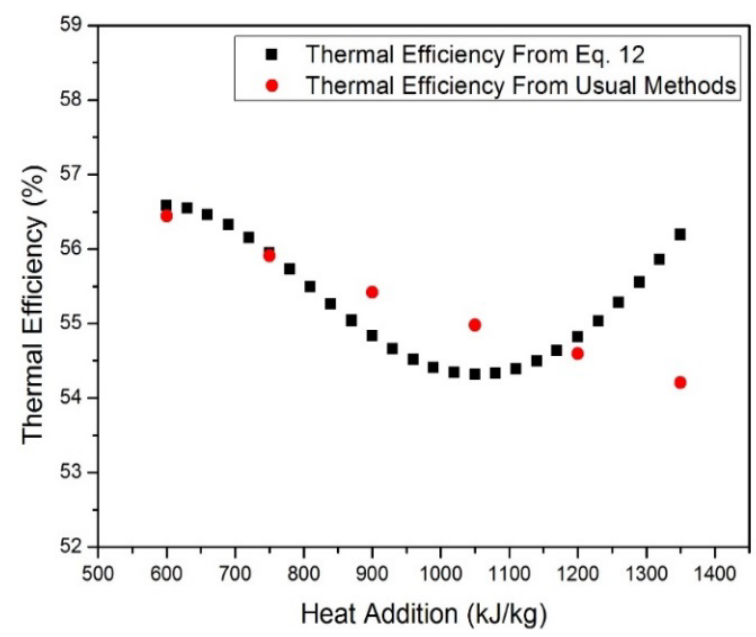

Figure 8. Effect of variation of energy input in thermal efficiency.

\section{CONCLUSIONS}

As seem in the paper it is useful for the engineers to implement methodologies and the proper data in simple software's for rapidly obtain the engine efficiency. Tests with the final equation were done and verified not differing too much from the real, being as a result, ideal for a superficial analysis. Such situations where it would not be necessary dig into complex calculations. Moreover, the equation developed is useful once allows a quick analysis of the efficiency when some initial values change, such as compression rate, temperature and input energy.

\section{REFERENCES}

Çengel, Y. A., and Boles, M. A., 2006, Thermodynamics: an Engineering Approach, Fifth Edition, McGraw-Hill.

Leff, H. S., 1987, Thermal Efficiency at Maximum Work Output: New Results for Old Engines, American Journal of Physics, Vol. 55, No. 7, pp. 602-610.

Costa, R. C., and Sodré, J. R., 2011, Compression Ratio Effects on an Ethanol/gasoline Fuelled Engine Performance, Applied Thermal Engineering, Vol. 31, No. 2-3, pp. 278-283. 